\title{
CLINICAL AND IMMUNOLOGICAL STUDY OF THE ORIGIN OF PROLIFERATIVE VITREORETI- NOPATHY IN TRAUMAS OF THE EYEBALL IN THE EARLY POSTTRAUMATIC PERIOD
}

Bezditko P. A., Levchenko L. I., Borisova L. Y Deynikhovskiy V. P.

Based on the analysis of immunoenzymatic study of the blood serum in 96 patients with injuries of the eye in the early posttraumatic period for cytokines: interleukin $1-\beta$, interleukin-6, circulating immune complexes, secretory immunoglobulin A, prostaglandin E - 2, it was found that proliferative vitreoretinopathy occurred in 58 cases $(60.4 \%)$ during the first month after injury. Patients with proliferative vitreoretinopathy had higher average rates of interleukin $1-\beta(29.7 \pm 4.4) \mathrm{pg} / \mathrm{ml}$ and indicators of interleukin-6 $(45.1 \pm 23.8) \mathrm{pg} / \mathrm{ml}$, secretory immunoglobulin $\mathrm{A}(3.4 \pm 0.3) \mathrm{g} / \mathrm{ml}$, the level of prostaglandin $\mathrm{E} 2$ was higher in patients without proliferative vitreoretinopathy $(5.4 \pm 0.5) \mathrm{pg} / \mathrm{ml}$, the level of circulating immune complexes was unchanged $(0.08 \pm 0.01) \mathrm{pg} / \mathrm{ml}$. These data must be taken into consideration by practical ophthalmologists.

УДК 617.753.29-06:617.736-007.243

\section{РОЛЬ МИОПИЧЕСКОГО ФОВЕОШИЗИСА В РАЗВИТИИИ МАКУЛЯРНОГО РАЗРЫВА СЕТЧАТКИ ПРИ МИОПИИ ВЫСОКОЙ СТЕПЕНИ}

\author{
Н. А. Ульянова, доцент кафедры офтальмологии, к. мед. н., \\ л. В. Венгер, и. о. зав.каф. офтальмологии, д. мед. н. \\ Одесский национальный медицинский университет
}

\begin{abstract}
В роботі вивчені особливості макулярної області сітківки методом спектральної оптичної когерентної томографії у пацієнтів з міопією високого ступеня. Обстежено 37 хворих з міопією високого ступеня, 14 осіб (26 очей) з рефракційним типом міопії високого ступеня; 18 осіб (36 очей) з високою осьовою міопією; 5 пацієнтів (5 очей) з високою осьовою міопією і наявністю наскрізного макулярного дефекту сітківки. Встановлено, що макулярні розриви сітківки при високій осьовій міопії морфологічно відрізняються від ідіопатичних і супроводжуються змінами базального комплексу та наявністю фовеошизису. Наявність фовеального ретиношизису відіграє ключову роль у патогенезі формування макулярних розривів у пацієнтів з високою осьової міопією.
\end{abstract}

Ключевые слова: миопия высокой степени, макулярный разрыв сетчатки, спектральная оптическая когерентная томография сетчатки.

Ключові слова: міопія високого ступеня, макулярний розрив сітківки, спектральна оптична когерентна томографія сітківки.

Введение. Макулярные разрывы сетчатки встречаются примерно у 3 из 1000 обследованных и являются достаточно частой причиной стойкого снижения центрального зрения у пациентов [1]. Основной разновидностью сквозных макулярных дефектов считаются идиопатические макулярные разрывы. Чаще всего заболевание развивается у женщин в возрасте 60-70 лет с нормальной или слабой гиперметропической рефракцией, причем риск развития макулярного отверстия на парном глазу в течение 5 лет составляет около $15 \%$ [2]. Увеличение заболеваемости близорукостью, в частности увеличение числа случаев высокой осевой формы данного вида аномалии рефракции, привело к тому, что второе место по частоте занимают разрывы сетчатки в макуле при высокой осевой миопии [5, 8].

Впервые данная патология сетчатки была описана Кнапом во второй половине XIX века
[2], однако до сих пор патогенез формирования сквозного макулярного отверстия остается офтальмологической энигмой. Согласно современным представлениям о стадиях данного заболевания - макулярное отверстие формируется вследствие центробежного расхождения фоторецепторов после отделения центральной части фовеолы. Пусковым механизмом, по-видимому, является переднезадняя витреофовеолярная тракция, связанная с аномальным прикреплением задней гиалоидной мембраны в области фовеолы [4]. Однако при высокой осевой миопии анатомотопографические особенности заднего полюса глаза могут создавать несколько другие предпосылки к развитию дефекта сетчатки, поэтому, на наш взгляд, актуальным для понимания патогенеза макулярного разрыва у данной категории боль-

(C) Н. А. Ульянова, Л. В. Венгер, 2012 
ных является изучение особенностей макулярной области при увеличенном переднезаднем размере глаза у миопов. Решение данного вопроса стало возможным с появлением метода спектральной оптической когерентной томографии сетчатки, который позволяет провести морфологический и морфометрический анализ слоев сетчатки в режиме реального времени, а также в динамике наблюдения.

Исходя из вышеизложенного, целью нашей работы является изучение особенностей макулярной области сетчатки методом спектральной оптической когерентной томографии у пациентов с миопией высокой степени.

МАТЕРИАЛ И МЕТОДЫ. Под наблюдением в клинике находились 37 больных (25 женщин и 12 мужчин) с миопией высокой степени в возрасте от 21 до 47 лет. В первую группу вошли 14 человек (26 глаз) с рефракционным типом миопии высокой степени, у которых средний сферический эквивалент рефракции составил $-8,1^{\mathrm{D}} \pm 0,03$, и преимущественно был обусловлен высокой преломляющей способностью роговицы, при этом переднезадний размер глаз в среднем составлял $(26,31 \pm 0,05)$ мм. Во вторую группу вошли 18 человек (36 глаз) с высокой осевой миопией. Сферический эквивалент плаз колебался от $-8,0^{\mathrm{D}}$ до -16,0 $0^{\mathrm{D}}$ и в среднем составил $-10,5^{D} \pm 0,6$. Переднезадний размер был от 25,7 до 30,6 мм и в среднем составлял $(27,36 \pm 0,4)$ мм. В третью группу наблюдения вошли 5 пациентов (5 глаз) с высокой осевой миопией и наличием сквозного макулярного дефекта сетчатки. Средний сферический эквивалент глаз составил $-11,2^{\mathrm{D}} \pm 0,5$. Переднезадний размер в среднем составлял $(27,76 \pm 0,4)$ мм.

Всем больным выполнено стандартное офтальмологическое обследование. Морфологические особенности макулярной области сетчатки изучали методом спектральной оптической когерентной томографии на аппарате «Soct Copernicus Optopol» в режиме 3D-сканирования с последующим анализом по стандарту «Macular analysis». Морфометрические показатели (толщина сетчатки, толщина слоя нервных волокон) определяли в фовеоле а также в стандартных секторах в пределах макулярной области.

Статистическая обработка полученных данных проведена с использованием дисперсионного анализа, критерия Ньюмена-Кейлса.

РЕЗУЛЬТАТЫ И ИХ ОБСУЖДЕНИЕ. В результате проведенных исследований было установлено, что у пациентов первой и второй групп с миопией высокой степени в центральных отделах глазного дна имелись отличия в толщине сетчатки в зависимости от вида высокой миопии (Табл. 1).

При исследовании методом спектральной оптической когерентной томографии толщина сетчатки оценивается как расстояние между двумя рефлектирующими средами, соответствующими внутренней пограничной мембране и слою пигментного эпителия сетчатки (ILM-RPE). Установлено, что на глазах с высокой осевой миопией отмечается тенденция к увеличению толщины сетчатки в фовеоле и во всех секторах в пределах пятимилли- метровой зоны. Известно, что на толщину сетчатки влияет наличие отека слоев, однако в группы наблюдения не включались пациенты с макулярным отеком. Толщина сетчатки может изменяться при наличии тракций со стороны задней гиалоидной мембраны при ее неполной отслойке. Количество пациентов с отслойкой задней гиалоидной мембраны в обеих группах наблюдения было сопоставимо. Как отмечалось в наших предыдущих публикациях, механизм утолщения сетчатки при высокой осевой миопии мы связываем с увеличением переднезаднего размера глаза, наличием задней миопической стафиломы и измененной конфигурации заднего полюса глаза, что влияет не только на архитектонику слоев, но и на толщину сетчатки в центре [3]. Задняя отслойка стекловидного тела, при которой нарушается его опорная функция, усугубляет имеющиеся морфологические изменения сетчатки в центральных отделах. Такое увеличение толщины сетчатки при условии количественного постоянства клеточного состава может свидетельствовать о снижении плотности и разрежении слоев сетчатки, что в свою очередь влияет на межклеточные взаимодействия в пределах сетчатой оболочки и подлежащей хориоидеи.

Таблица 1

Толщина сетчатки в макулярной области у пациентов с миопией высокой степени ( $\mathrm{M} \pm \mathrm{m}$, мкм)

\begin{tabular}{|l|c|c|}
\hline $\begin{array}{c}\text { Сектор исследования ма- } \\
\text { кулярной области сетчатки }\end{array}$ & $\begin{array}{c}\text { I группа } \\
\text { (рефракционная } \\
\text { миопия высокой } \\
\text { степени) } \\
\text { (n=26 глаз) }\end{array}$ & $\begin{array}{c}\text { II группа } \\
\text { (осевая миопия } \\
\text { высокой сте- } \\
\text { пени) } \\
\text { (n=36 глаз) }\end{array}$ \\
\hline Фовеола & $202 \pm 4,3$ & $216 \pm 4,9^{*}$ \\
\hline Внутренний верхний & $269 \pm 3,34$ & $275 \pm 3,32$ \\
\hline Внутренний височный & $258 \pm 3,05$ & $264 \pm 3,3$ \\
\hline Внутренний нижний & $270 \pm 3,61$ & $272 \pm 2,98$ \\
\hline Внутренний носовой & $268 \pm 3,31$ & $283 \pm 2,71^{*}$ \\
\hline Наружный верхний & $247 \pm 2,49$ & $254 \pm 3,3$ \\
\hline Наружный височный & $231 \pm 2,47$ & $243 \pm 3,41^{*}$ \\
\hline Наружный нижний & $233 \pm 3,03$ & $251 \pm 2,83^{*}$ \\
\hline Наружный носовой & $257 \pm 2,57$ & $268 \pm 2,71^{*}$ \\
\hline
\end{tabular}

Примечан ие. * - p $<0,05$ по сравнению с I группой.

Среди выявленных морфологических изменений сетчатки в макуле у $45 \%$ пациентов второй группы при высокой осевой миопии наиболее показательными оказались участки очаговой атрофии пигментного эпителия сетчатки, в частности, случаи «географической» атрофии, а также увеличение ширины гипоэхогенного участка, соответствующего наружному сетчатому слою, что в крайней степени выраженности трактуется как миопический фовеошизис (рис. 1). Как правило, выявленные изменения сочетались с наличием задней миопической стафиломы и перипапиллярной атрофии пигментного эпителия сетчатки (рис. 2). 


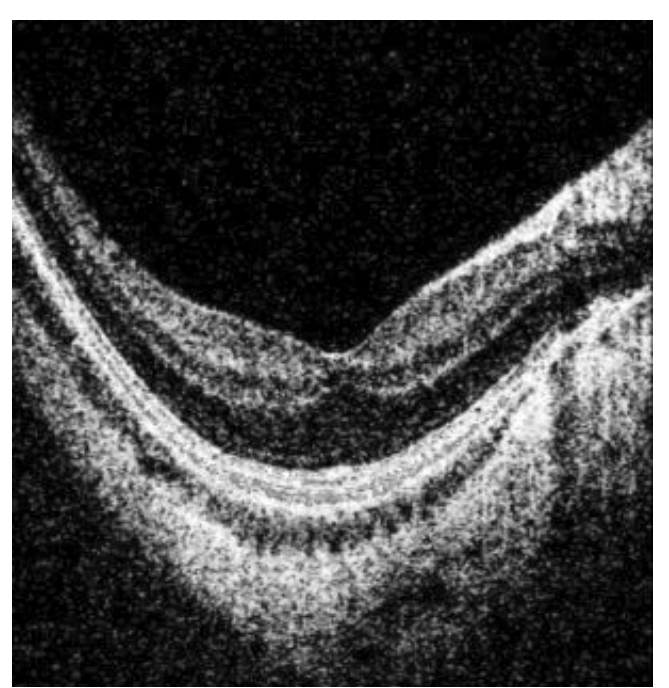

Рис. 1. Сканограмма макулярной области сетчатки пациентки А., 46 л., миопия (-10,0 $)$, переднезадний размер глаза 28,2 мм.

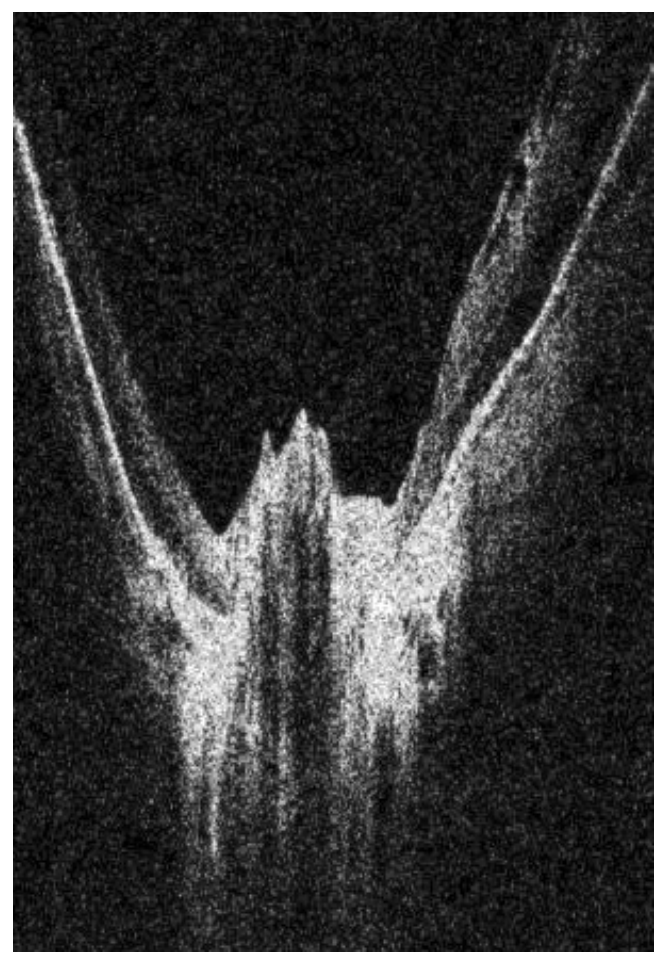

Рис. 2. Сканограмма диска зрительного нерва пациента В., 42 г., миопия $\left(-12,0^{\mathrm{D}}\right)$, переднезадний размер глаза 29,1 мм.

У всех пациентов третьей группы выявлены грубые дистрофические изменения сетчатки в заднем полюсе глаза, связанные с атрофией пигментного эпителия. В одном случае обнаружено парамакулярное субретинальное кровоизлияние. Диаметр сквозного дырчатого дефекта сетчатки колебался от 350 до 420 мкм. Витреоретинальная тракция отмечена на одном глазу и сопровождалась отслойкой внутренней пограничной мембраны в парафовеолярной области. У всех пациентов с макулярными разрывами на фоне высокой осе- вой миопии отмечены признаки фовеошизиса, а именно - увеличение толщины сетчатки по краям разрыва без признаков мелко- или крупнозернистого отека сетчатки, увеличение ширины гипоэхогенного пространства в проекции наружного сетчатого слоя сетчатки. Выявленные разрывы сетчатки при миопии высокой степени в отличие от идиопатических сопровождались нарушением прилегания сетчатки на границе дефекта и появлением гипоэхогеннных зазоров под краями разрыва (рис. 3).

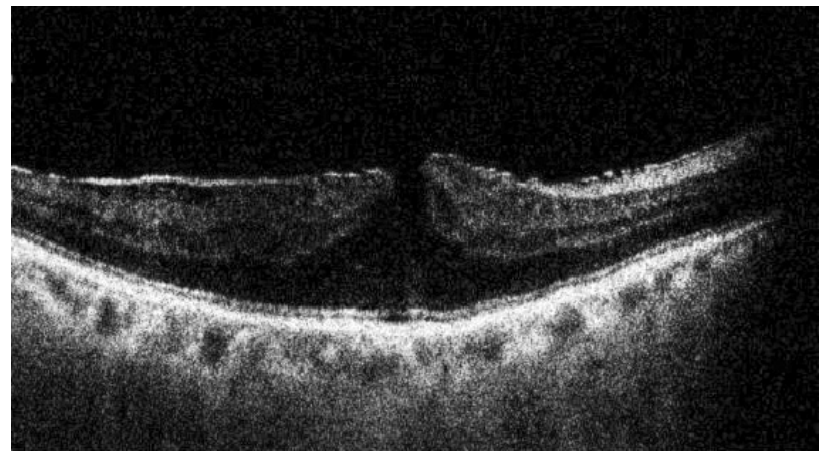

Рис. 3. Сканограмма макулярной области сетчатки пациентки П., 47 л., миопия $\left(-9,0^{D}\right)$, переднезадний размер глаза 27,9 мм.

Согласно концепции формирования идиопатического макулярного разрыва, предложенной Гассом, образование отверстия происходит в результате тангенциальных тракций, возникающих вдоль задней поверхности стекловидного тела [7]. Сила тракции значительно возрастает в момент отслойки задней гиалоидной мембраны, когда под действием тракций со стороны задней витреальной коры натягивается фовеолярная сетчатка с образованием так называемой интраретинальной кисты. Однако не все макулярные разрывы сопровождаются тракцией. По мнению ряда авторов, в данном случае в формировании разрыва определенную роль играет истончение сетчатки, причины которого на данный момент не до конца изучены [1].

В отличие от идиопатических, при макулярных разрывах на фоне миопической макулопатии первостепенную роль в патогенезе формирования отверстия в фовеоле, на наш взгляд, играет наличие фовеошизиса и разрежение ткани сетчатки в парафовеолярной зоне, связанное с характерным для миопической стафиломы выпячиванием заднего полюса глаза вследствие деформации склеры. Очевидной становится центростремительная дислокация сетчатой оболочки, которая в отличие от склеры, не обладает эластичностью. В таких условиях происходит расслоение сетчатки и формирование фовеошизиса в проекции, где задний контур имеет больший радиус кривизны. Следовательно, даже при отсутствии витреоретинальной тракции созда- 
ются предпосылки для расхождения фоторецепторов и отделения фовеолы от пигментного эпителия. Данные особенности патогенеза макулярного разрыва у миопов объясняют тот установленный факт, что в $50 \%$ случаев макулярные разрывы при миопии высокой степени сопровождаются центральной отслойкой сетчатки, что не характерно для идиопатических разрывов [9].

Согласно данным литературы, почти у $70 \%$ больных с наличием отслойки внутренней пограничной мембраны и центральным ретиношизисом развиваются макулярные разрывы сетчатки $[6,10]$. На наш взгляд, наличие тракционной миопической макулопатии способствует реализации предрасположенности к формированию разрыва при высокой осевой миопии. Однако преморбидным фоном для развития данного осложнения является наличие миопического фовеошизиса.

\section{ВЫВОДЫ}

1. Макулярные разрывы сетчатки при высокой осевой миопии морфологически отличаются от идиопатических и сопровождаются изменениями базального комплекса и наличием фовеошизиса.

2. Наличие фовеального ретиношизиса играет ключевую роль в патогенезе формирования макулярных разрывов у пациентов с высокой осевой миопией.

3. Морфологические изменения сетчатки в зоне макулярного разрыва при высокой осевой миопии, выявленные методом спектральной оптической когерентной томографии, позволяют расширить представления о патогенезе данной патологии и, следовательно, целенаправленно планировать комплекс патогенетически ориентированного лечения.

\section{ЛИТЕРАТУРА}

1. Заболевания глазного дна / Кански Дж.Дж., Милевски С. А., Дамато Д. Э. и соавт.; Пер. с англ.; Под общ. ред. чл. - корр. РАМН, проф. Аветисова С. Э. - М.: МЕДпрес-информ, 2008. - 424 с.

2. Оптическая когерентная томография в диагностике глазных болезней / Под ред. Щуко А. Г., Малышева В. В. - М.: ГЭОТАР-Медиа, 2010. - 128 с.

3. Ульянова Н. А. Изменение витреоретинального интерфейса при высокой миопии по данным спектральной оптической когерентной томографии / Н. А. Ульянова // Офтальмол. журн. - 2012. - № 2. - С. 22-25.

4. Bainbridge $\mathbf{J}$. Macular holes: vitreoretinal relationships and surgical approaches/ J. Bainbridge, E. Herbert, Z. Gregor // Eye. - 2008. - № 10. - P. 1301-1309.

5. Faghihi H. Optical coherence tomographic findings in highly myopic eyes / H. Faghihi, F. Hajizadeh, M. RiaziEsfahani // J. ophthalmic and Vision Research. - 2010. Vol. 5, № 2. - P. 110-121.

6. Imaging the eye from front to back with RTVue FourierDomain Optical Coherence Tomography / D. Huang, Jay S. Duker, J. G. Fujimoto [at al.]. - NJ: SLACK Incorporated, 2010. $-268 \mathrm{p}$.

7. Johnson M. W. Posterior vitreous detachment: evolution and complications of its early stages / M. W. Johnson // Am. J. Ophthalmology. - 2010. - Vol. 149. - P. 371-382.

8. Mitry D. Recent trends in the management of maculopathy secondary to pathological myopia / D. Mitry, H. Zambarakji // Graefes Arch. Clin. Exp. Ophthalmol. - 2012. Vol. 250. - P. 3-13.

9. Müller B. Myopic traction maculopathy - vitreoretinal traction syndrome in high myopic eyes and posterior staphyloma / B. Müller, A. M. Joussen // Klin. Monbl. Augenheilkd. - 2011. - Vol. 228. - P. 771-779.

10. Ultrastructure of internal limiting membrane in myopic foveoschisis / H. Bando, Y. Ikuno, J. S. Choi [at al.] // Am. J. Ophthalmology. - 2005. - Vol. 139. - P. 197-199.

Поступила 14.11.2012

Рецензент к. м. н. Н. Н. Уманец

\section{THE ROLE OF MYOPIC FOVEASCHISIS IN DEVELOPMENT OF MACULAR HOLES IN HIGH DEGREE MYOPIA \\ Ulyanova N. A., Venger L. V. \\ Odessa, Ukraine}

The paper gives the results of examination of the retinal macular area by spectral optical coherence tomography in patients with high degree myopia. There were examined 37 patients with high degree myopia, 14 patients (26 eyes) with refractive type of myopia, 18 patients (36 eyes) with high axial myopia, 5 patients ( 5 eyes) with high axial myopia and presence of the macular holes. It was established that the macular holes in high axial myopia were morphologically different from idiopathic ones and were associated with changes in the basal complex and presence of foveoschisis. The presence of foveoschisis has a very important role in pathogenesis of the macular holes in patients with high degree axial myopia. 